\title{
Mortality of women with ductal carcinoma in situ of the breast: a population-based study from the Girona province, Spain (1994-2013)
}

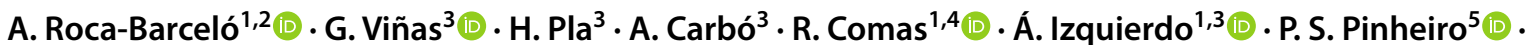 \\ L. Vilardell ${ }^{1}$ (D) M. Solans ${ }^{1,6,7,8}$ iD $\cdot$ R. Marcos-Gragera ${ }^{1,6,8,9}$ iD
}

Received: 20 June 2018 / Accepted: 17 November 2018 / Published online: 10 December 2018

(c) The Author(s) 2018

\begin{abstract}
Purpose We aim to comprehensively describe the incidence and mortality trends of ductal carcinoma in situ (DCIS) in the Girona province, Spain (1994-2013) and to estimate the all-cause mortality excess risk of diagnosed women.

Methods Age-standardized rates of DCIS were estimated between 1994 and 2013. Standard mortality ratios (SMR) and absolute excess mortality were calculated overall and by tumor and patient characteristics. A sensitivity analysis was conducted excluding cases with a subsequent invasive breast cancer (sIBC).

Results Of the 641 women included, 56 died (follow-up time: 8.4 person-years). Between 1994 and 2013, a significant increase in incidence and decrease in mortality was identified among women aged between 50 and 69 years old. Neoplasms and circulatory system disease were the most common causes of death. No excess risk of death was found overall, except for women aged $<50$ years $(\mathrm{SMR}=3.44,95 \% \mathrm{CI} 1.85 ; 6.40)$ and those with a sIBC (SMR $=2.51,95 \%$ CI $1.26 ; 5.02)$, risk that lessened when cases with sIBC were excluded. Patients with sIBC also showed an excess risk (SMR =2.29, 95\% CI 1.03; 5.10).

Conclusions Among women aged 50-69 years old, incidence of DCIS has significantly increased yet mortality has decreased. Overall, the all-cause mortality risk of women diagnosed with DCIS remains similar to that of the general population except for women diagnosed before age 50 and those with sIBC, who showed a significant increased risk. Differential management of these patients should be considered.
\end{abstract}

Keywords Ductal carcinoma in situ $\cdot$ Standardized mortality ratio $\cdot$ Incidence $\cdot$ Mortality $\cdot$ Spain

Electronic supplementary material The online version of this article (https://doi.org/10.1007/s12094-018-1994-1) contains supplementary material, which is available to authorized users.

A. Roca-Barceló

ainarb16@gmail.com; a.roca-barcelo@imperial.ac.uk

1 Epidemiology Unit and Girona Cancer Registry, Oncology Coordination Plan, Department of Health, Autonomous Government of Catalonia, Catalan Institute of Oncology, Carrer del Sol, 15, 17004 Girona, Spain

2 UK Small Area Health Statistics Unit, MRC-PHE Centre for Environment and Health, Department of Epidemiology and Biostatistics, School of Public Health, Imperial College London, London, UK

3 Department of Medical Oncology, Institut Català d'Oncologia Hospital Universitari de Girona Dr Josep Trueta, Girona, Spain

4 Oncology Data Science (ODysSey) Group, Vall d' Hebron University Hospital and Institute of Oncology (VHIO), Barcelona, Spain
5 Department of Epidemiology, University of Miami Miller School of Medicine, Slvester Comprehensive Cancer Center, Miami, FL, USA

6 Centro de Investigación Biomédica en Red: Epidemiología y Salud Pública (CIBERESP), Avenida Monforte de Lemos, 3-5, Pabellón 11, Planta 0, 28029 Madrid, Spain

7 Research Group on Statistics, Econometrics and Health (GRECS), University of Girona, Carrer de la Universitat de Girona 10, 17003 Girona, Spain

8 Descriptive Epidemiology, Genetics and Cancer Prevention Group, Biomedical Research Institute (IDIBGI), Girona, Spain

9 Research Group on Statistics, Econometrics and Health (GRECS), University of Girona, Girona, Spain 


\section{Introduction}

Ductal carcinoma in situ (DCIS) is a noninvasive breast cancer (BC) originating from the cells within the breast ducts. It consists of lesions that can go from low-grade and indolent to high-grade, aggressive tumors that can evolve to an invasive disease. It is regarded as the most common type of in situ BC (80-90\%) [1]. Most DCIS are diagnosed by routine mammography. Indeed, its incidence has increased markedly since 1980 worldwide [2-4] mainly related to the spread use of opportunistic mammography and to the implementation of population-based screening programs [5-9]. It is estimated that over $20 \%$ of all screened detected BC are DCIS [5]. Upward trends have been reported in several regions, including in the Girona province (Spain) where a marked increase, especially among women aged 50-69 years old, was observed between 1992 and 1996, attributed to the spread in mammography use in the region [9].

The standard treatment for DCIS involves local breastconservative surgery followed by radiotherapy (RT) or total mastectomy with/without endocrine therapy. The clinical benefit of early detection and treatment for DCIS remains unclear; therefore, the individualized treatment is a clinical challenge. Studies on the risks of death for women diagnosed with DCIS can help provide a better understanding of the disease and better inform current practice and treatment prescription. Most of the current evidence is on BC-specific survival and mortality $[10,11]$. However, cause-specific mortality comparisons may be biased due to misclassification in the certified causes of death [12] and do not account for deaths indirectly related to the cancer or its treatment [13]. Competing causes of death and all-cause mortality would allow to overcome these limitations. Few studies have compared all-cause mortality rates of women with DCIS to the general population, most of which are in northern Europe [14-17] and the US [18]. Considering the possible differences in prevention plans, detection and treatment approaches between countries [19-22], it becomes relevant to provide evidence on all-cause mortality for patients diagnosed with a DCIS in regions where is not yet available, such as Southern Europe.

Hence, this study aimed to update the incidence and mortality trends for DCIS in the Girona province, North-Eastern Spain, between 1994 and 2013, and to explore whether women diagnosed with DCIS have an excess risk of allcause death compared to the general population.

\section{Methods}

\section{Data collection}

Data were extracted from the population-based Girona Cancer Registry (GCR) containing data on the Girona province, which covered a population of 371,622 women in July, 2013 [23]. The estimated completeness of the registry for all-sites combined was $95 \%$ in 2010-2012 [24].

\section{Cohort selection}

We restricted our analyses to women diagnosed with a histologically primary DCIS (ICD-O-3: D050-D059) between 1994 and 2013. Women with bilateral tumors and those diagnosed at time of death were excluded. For women with synchronous tumors $(n=4)$, only the tumor with the highest grade was included. Women were followed from the date of diagnosis until death or end of follow-up (31st December, 2014), whichever came first. Information on $\operatorname{siBC}(n=31)$ was collected, with follow-up until 31st December 2014.

We collected information relating to the patient (i.e., age at diagnosis), the tumor [i.e., grade, histological type, tumor size, and estrogen receptor (ER) expression], the type of treatment received (i.e., breast-conservative surgery, endocrine therapy or radiotherapy), the diagnostic method [i.e., whether it was detected through the "Programa de Detecció Precoç del Càncer de Mama" (PDPCM), the regional population-based breast cancer screening program], and whether there was a subsequent invasive breast cancer (sIBC). Age was classified as $<50,50-69$ and $>69$ years old, since 50-69 is the age band targeted by the PDPCM.

\section{Statistical analysis}

We estimated annual incidence and mortality rates, overall and by age group. All rates were age-standardized (ASR) using the European standard population. For the temporal trends, we used Joinpoint regression. Case counts were modelled as log-linear piece-wise functions of time with Poisson variance and a log-population offset (9), using the statistical software package Joinpoint Version 4.6.0. (10). The model fit and the number of joinpoints were assessed with the modified Bayesian information criterion. Significance was set at $p<0.05$ and tested using the Monte Carlo Permutation method. The slope of each of the fitted log-linear functions defined the annual percentage change (APC) of that segment.

To measure the excess mortality we used standardized mortality ratios (SMRs) as the ratio between observed and expected deaths. The expected number of deaths was estimated from age-, sex- and calendar-year-specific mortality rates for the Girona province. Absolute excess mortality (AEM) was calculated as the absolute difference between the expected and observed deaths divided by the personyears at risk and multiplied by 1000 . Results were stratified by tumor and patient characteristics, sIBC and method of 
diagnosis (i.e., screening or opportunistic). For the latter, the analysis was restricted to women 50-69 years old diagnosed after 2000, as this is the eligible age range and year of implementation of the population-based screening program in the area. We also conducted a sensitivity analysis excluding women with a sIBC to determine the fraction of SMR potentially attributable to DCIS without a SIBC (Supplementary Material).

Mid-year population estimates and mortality rates were specific for the Girona province and obtained from the Institut d'Estadística de Catalunya, IDESCAT(6). Significance level was set at $95 \%$ confidence interval (95\% CI). Analyses were conducted in Stata version 13 [25].

\section{Results}

\section{Population characteristics}

Between 1st January 1994 and 31st December 2013, 641 women were diagnosed with DCIs in the Girona province, northeastern Spain. Table 1 shows the clinical presentation, tumor characteristics, diagnostic method (i.e., screening or opportunistic diagnosis), and treatment choices of the patients by survival status.

Median age (interquartile range) at diagnosis was 54 $(48 ; 63)$ years. The majority of deceased women were diagnosed prior to 2002 . Large tumors, i.e., $\geq 2 \mathrm{~cm}$, were slightly more common among deceased women (41.2\% vs. $29.1 \%)$, yet differences were not significant. Most women had tumors with a positive estrogen receptor profile (79.7\%). The usage of routine screening tools among women within the elective age range for the routine screening program was similar to the usage of opportunistic screening, yet the proportion of opportunistic screening (83.3\%) was significantly higher amongst deceased women ( $p$ value $<0.014$ ). Most women underwent breast-conservative surgery (85.6 and 70.9\%, respectively). The use of hormonal treatment and radiotherapy varied across the groups, both being less commonly applied to deceased women. Overall, 32 women suffered a sIBC of which 8 died during the follow-up period ( $p$ value: $0.001)$.

\section{Incidence}

Between 1994 and 2013, the incidence of DCIS significantly increased among women aged 50-69 years old $(\mathrm{APC}=4.1$, $95 \%$ CI $2.0 ; 6.3, p$ value $<0.05$, Fig. 1$)$. No significant increment over time was observed among women aged under 50 or over 69 years old. According to the Jointpoint analysis, trends over time followed a unique pattern and no statistically significant change in the increment was found (i.e., absence of joint point).

\section{All-cause mortality}

Between 1994 and 2013, we observed a significant reduction in all-cause mortality rates only for women aged between 50 and 69 years old, with an APC of $-9.0 \%$ (95\% CI - 12.1; - 5.8, Fig. 2). According to the Jointpoint analysis, trends over time followed a unique pattern and no statistically significant change in the trends was found.

Mean (SD) follow-up time was 8.4 (5.2) person-years (Table 1). During the study period, 56 women $(8.7 \%)$ died. The most common causes of death reported in the death certificate were neoplasms $(n=26,46.4 \%)$, with BC representing $14.3 \%$ of all cancer-related events followed by circulatory system diseases $(n=12,21.4 \%)$ (Table 2). Neoplasms, and specifically neoplasms of the breast were the most common causes of death in all age groups. Most common other neoplasms were those from the digestive and female genitals. Circulatory system-related deaths were only remarkably high among women aged over 50 years old (26.1\%).

Overall, women diagnosed with a DCIS showed no difference in all-cause mortality compared to the general population $(\mathrm{SMR}=1.04 ; 95 \%$ CI 0.80; 1.36 , Table 3$)$. For most other categories the observed number of deaths was lower than the expected; however, these differences were not statistically significant except for age at diagnosis and presence of a sIBC. Women aged $<50$ years old at diagnosis, showed a remarkable increased mortality ratio $(\mathrm{SMR}=3.44 ; 95 \% \mathrm{CI}$ $1.85 ; 6.40)$, which represented an AEM of four deaths compared to that expected for the area and study period. Similarly, women with a registered SIBC showed an increased risk of all-cause fatalities ( $\mathrm{SMR}=2.51 ; 95 \%$ CI $1.26 ; 5.02)$, which translated in almost 13 excess deaths. When patients with a SIBC were excluded (Table S2), the SMR in the youngest group decreased $(\mathrm{SMR}=2.29 ; 95 \% \mathrm{CI} 1.03 ; 5.10)$ (Table S2).

\section{Discussion}

Despite DCIS being associated with good prognosis, its exact impact on all-cause mortality remains unclear. The current population-based study provides updated incidence and mortality rates for DCIS and explores the SMR of women diagnosed with a DCIS between 1994 and 2013 in the Girona province, Spain.

\section{Incidence}

Our results showed no significant change in the incidence rate of DCIS among women aged under 50 or over 69 years old, between 1994 and 2013. However, there was a significant increase of $4.1 \%$ per year $(95 \%$ CI $2.0 ; 6.3)$ in the incidence of DCIS among women aged 50-69 years old. 
Table 1 Characteristics at diagnosis for all women in the cohort (1994-2013)

\begin{tabular}{|c|c|c|c|c|c|c|c|}
\hline \multirow[t]{2}{*}{ Characteristics } & \multicolumn{2}{|l|}{ Total } & \multicolumn{2}{|l|}{ Alive } & \multicolumn{3}{|l|}{ Death } \\
\hline & $n$ & $\%$ & $n$ & $\%$ & $n$ & $\%$ & $p$ value \\
\hline Person-years & 5426.7 & & 4955.9 & & 470.8 & & \\
\hline Follow-up time, mean (SD) years & $8.4(5.2)$ & & $8.5(5.2)$ & & $8.4(5.1)$ & & 0.930 \\
\hline Age, mean (SD) years & $55.9(11.3)$ & & $54.8(10.3)$ & & $66.9(14.4)$ & & $<0.005^{*}$ \\
\hline Age, median $(\mathrm{Q} 1 ; \mathrm{Q} 3)$ years & $54(48 ; 63)$ & & $54.0(48 ; 61)$ & & $69.5(58 ; 77.5)$ & & \\
\hline \multicolumn{8}{|l|}{ Age group } \\
\hline$<50$ years old & 185 & & 175 & 30.0 & 10 & 17.9 & $<0.005^{*}$ \\
\hline $50-69$ years old & 376 & & 358 & 61.2 & 18 & 32.1 & \\
\hline$>69$ years old & 80 & & 52 & 8.9 & 28 & 50.0 & \\
\hline \multicolumn{8}{|l|}{ Year at diagnosis } \\
\hline 1994-2002 & 204 & 31.8 & 162 & 27.7 & 42 & 75.0 & $<0.005^{*}$ \\
\hline 2003-2013 & 437 & 68.2 & 423 & 72.3 & 14 & 25.0 & \\
\hline \multicolumn{8}{|l|}{ Grade } \\
\hline I & 57 & 8.9 & 54 & 36.5 & 3 & 37.5 & $0.001 *$ \\
\hline II & 97 & 15.1 & 94 & 48.2 & 3 & 37.5 & \\
\hline III & 103 & 16.1 & 101 & 23.1 & 2 & 25.0 & \\
\hline Unknown/unclassified & 384 & - & 336 & - & 48 & - & \\
\hline \multicolumn{8}{|l|}{ Tumor size } \\
\hline$<2 \mathrm{~cm}$ & 100 & 69.4 & 90 & 70.9 & 10 & 58.8 & 0.171 \\
\hline$\geq 2 \mathrm{~cm}$ & 44 & 30.6 & 37 & 29.1 & 7 & 41.2 & \\
\hline Unknown/unclassified & 537 & - & 458 & - & 79 & - & \\
\hline \multicolumn{8}{|l|}{ Estrogen receptor } \\
\hline Positive & 329 & 79.7 & 319 & 80.8 & 10 & 55.6 & $<0.005^{*}$ \\
\hline Negative & 84 & 20.3 & 76 & 28.6 & 8 & 44.4 & \\
\hline Unknown/unclassified & 228 & - & 190 & - & 38 & - & \\
\hline \multicolumn{8}{|l|}{ Breast conservative surgery } \\
\hline Yes & 539 & 84.4 & 500 & 85.6 & 39 & 70.9 & $0.002 *$ \\
\hline No & 100 & 15.6 & 84 & 14.4 & 16 & 29.1 & \\
\hline Unknown/unclassified & 2 & - & 1 & - & 1 & - & \\
\hline \multicolumn{8}{|l|}{ Endocrine treatment } \\
\hline Yes & 243 & 47.1 & 236 & 50.4 & 7 & 14.6 & $<0.005^{*}$ \\
\hline No & 273 & 52.9 & 232 & 49.6 & 41 & 85.4 & \\
\hline Unknown/unclassified & 125 & - & 117 & - & 8 & - & \\
\hline \multicolumn{8}{|l|}{ Radiotherapy } \\
\hline Yes & 240 & 51.7 & 233 & 55.6 & 7 & 15.6 & $<0.005^{*}$ \\
\hline No & 224 & 48.3 & 186 & 44.4 & 38 & 84.4 & \\
\hline Unknown/unclassified & 177 & - & 166 & - & 11 & - & \\
\hline \multicolumn{8}{|l|}{ Diagnostic method ${ }^{\mathrm{a}}$} \\
\hline Screening & 185 & 49.7 & 182 & 51.4 & 3 & 16.7 & $<0.014 *$ \\
\hline Opportunistic & 187 & 50.3 & 172 & 48.6 & 15 & 83.3 & \\
\hline Unknown & 4 & - & 4 & - & 0 & - & \\
\hline \multicolumn{8}{|l|}{ Invasive relapse $\mathrm{e}^{\mathrm{b}}$} \\
\hline Yes & 32 & 5.0 & 24 & 4.1 & 8 & 14.3 & $0.001 *$ \\
\hline No & 609 & 95.0 & 561 & 95.9 & 48 & 85.7 & \\
\hline Total & 641 & & 585 & & 56 & & \\
\hline
\end{tabular}

Percentages are given over the non-missing values. $p$ values are estimated for the whole sample ${ }^{*} p<0.05$

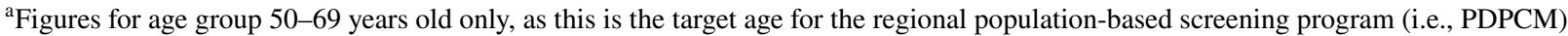

${ }^{b}$ Follow-up until 31st December 2014 


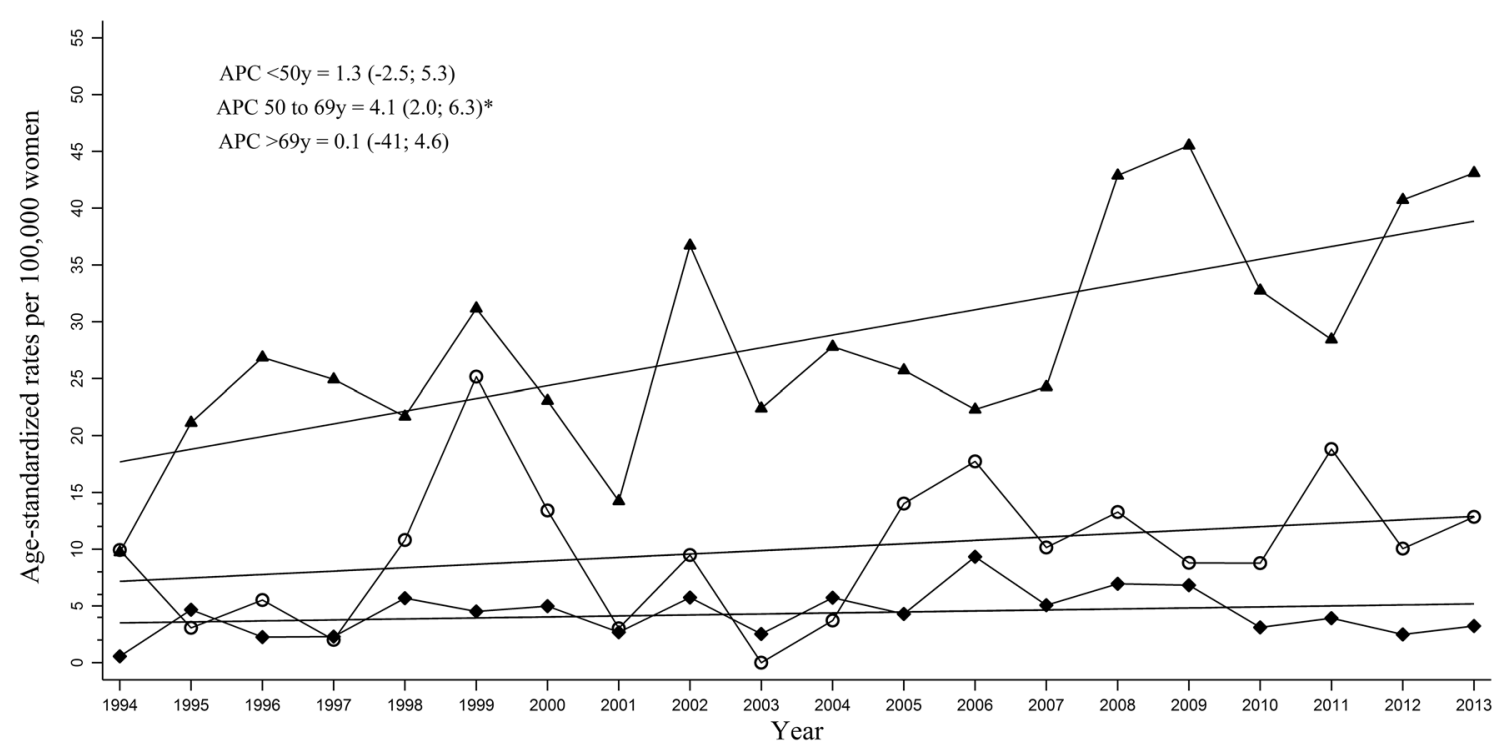

Fig. 1 Age-standardized annual incidence rates of DCIS among women aged $<50$ (black diamond), 50-69 (black triangle) and $>69$ years old (white circle). Dotted lines for linear trend. *Significant trend $(p$ value $<0.05)$

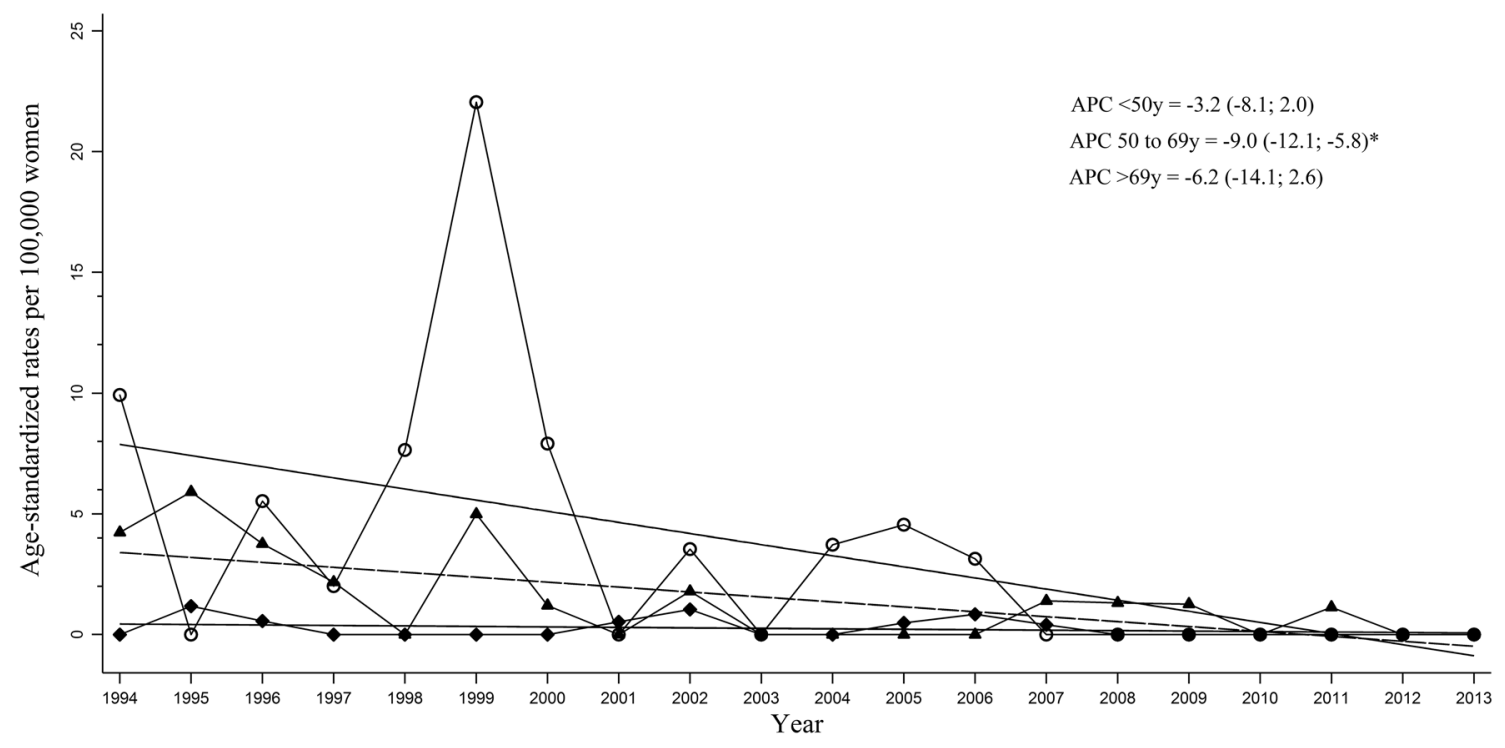

Fig. 2 Age-standardized annual mortality rates of DCIS among women aged $<50$ (black diamond), 50-69 (black triangle) and $>69$ years old (white circle). Dotted lines for linear trend. *Significant trend $(p$ value $<0.05)$

This age band corresponds to that targeted by the national population-based screening program, the PDPCM [26]. This program was introduced in 2000 and widely implemented all over the region in 2002. Similar upwards trends have been observed worldwide for the last decades and associated with the usage of mammography [4-8]. The participation on routine screenings had previously been reported by Puig-vives et al. [9] to be associated with an increased detection rate and thus, increased incidence in the Girona province, especially between 1992 and 1996.
Between 1997 and 2007, they observed a 2.0\% increase per year $(95 \% \mathrm{CI}-1.8 ; 6.0)$, yet this was not significant. According to Roman et al. (2013), screen-detected DCIS in Spain increased at a steady 2.5\% per year (95\% CI 1.3; 3.8) between 1992 and 2006. No plateau effect has been yet described in later years and thus, it is plausible that the detection rate has not yet reached a saturation point and continues to contribute to increase the incidence rates of DCIS in the region. This would be supported by recently published data on the evaluation of the PDPCM 
Table 2 Causes of death as reported in the death certificate

\begin{tabular}{|c|c|c|c|c|c|c|c|}
\hline \multirow[t]{2}{*}{ Cause of death } & \multicolumn{2}{|c|}{ Total } & \multicolumn{2}{|c|}{$<50$ years old } & \multicolumn{2}{|c|}{$\geq 50$ years old } & \multirow[t]{2}{*}{ Observed ICD-10 code } \\
\hline & $n$ & $\%$ & $n$ & $\%$ & $n$ & $\%$ & \\
\hline Neoplasms & 26 & 46.4 & 9 & 90.0 & 21 & 45.7 & \\
\hline Breast cancer & 8 & 14.3 & 4 & 40.0 & 4 & 8.7 & C509; D430; D489 \\
\hline Other tumors & 18 & 32.1 & 5 & 50.0 & 18 & 39.1 & $\begin{array}{l}\mathrm{C} 159 ; \mathrm{C} 189 ; \mathrm{C} 20 ; \mathrm{C} 259 ; \mathrm{C} 349 ; \mathrm{C} 499 ; \\
\quad \mathrm{C} 539 ; \mathrm{C} 56 ; \mathrm{C} 719 ; \mathrm{C} 859 ; \mathrm{C} 917 ; \mathrm{C} 959\end{array}$ \\
\hline Circulatory system diseases & 12 & 21.4 & 0 & 0 & 12 & 26.1 & I10; I119; I219; I340; I509; I639; I64; I678 \\
\hline Miscellaneous $^{\mathrm{a}}$ & 6 & 10.7 & 1 & 10.0 & 5 & 10.9 & A419; B182. F019; X495 \\
\hline NS disease & 3 & 5.4 & 0 & 0 & 3 & 6.5 & G309; G952 \\
\hline Respiratory system diseases & 3 & 5.4 & 0 & 0 & 3 & 6.5 & J449; J841; J988 \\
\hline Digestive system diseases & 3 & 5.4 & 0 & 0 & 3 & 6.5 & K509; K746 \\
\hline Genitourinary system & 2 & 3.6 & 0 & 0 & 2 & 4.3 & N189; N19 \\
\hline Total & 56 & 100.0 & 10 & 100.0 & 46 & 100.0 & \\
\hline
\end{tabular}

NS nervous system

${ }^{\mathrm{a}}$ Includes codes of different nature with only one patient each

in the Girona province for the 2014-2015 cycle, which has reached the highest ever registered coverage and participation rates since its implementation, i.e., $81.86 \%$ and $71.39 \%$, respectively [27]. Our study, with 7 years more worth of data than in Puig-vives et al. [9], may have been able to capture these trends (Figs. 1 and 2).

\section{Mortality}

Our results only showed a significant change in mortality trends among women aged between 50 and 69 years old $(\mathrm{APC}=-9 \%$; 95\% CI $-12.1 ;-5.8)$. Treatment has been related to mortality likelihood $[15,28]$ and thus, changes over time in treatment choices and protocols [28] could have impacted on mortality trends. The lack of significance in the trends of any group except for women aged between 50 and 69 years old could reflect the impact on survival of early detection through the participation to the routine mammography screening program. With the improvements in radiological and pathological assessment there has been a decrease in the number of unrecognized invasive $\mathrm{BC}$ infiltrations-linked to especially poor survival prognosis-at DCIS diagnosis. In addition, the extended implementation of screening programs has been related to an increment in over diagnosis $[29,30]-$ i.e., the diagnosis of a lesion that will never cause symptoms or death during a patient's lifetime. This is magnified if adherence to screening programs is high, as reported in a meta-analysis of intention-to-treat randomized control trials conducted by Jacklyn et al. [31]. Finally, adherence to screening programs has also been positively associated with women with more health-conscious behaviors, with less comorbidities and from higher socio-economic classes; the health screen effect [32-34].
All these could explain the significant negative trends in all-cause mortality rates observed only among women aged 50-69 years old. The lower risk of all-cause death among women diagnosed through screening compared to the general population, yet not significant, further supports this finding. The magnitude of the risk estimate and its lack of significance could be partially attributed to the associated risk of physical, psychological and financial harm due to overdiagnosis and treatment that has been associated with mammography use $[30,35]$.

Overall, women diagnosed with DCIS in our study did not show an increased risk of death. Treatment benefits could partially explain these results as evidence suggest improvements in survival for certain treatment choices [36]. However, no significant difference in the risk of death was observed across treatment branches. This is in line with other studies reporting no differences in survival and mortality for radiotherapy, endocrine therapy and conservative breast surgery use [37, 38]. In addition, treatment choices are highly linked to patient and tumor characteristics [39] and so, it is impossible to know from the data the extent to which the low risk of death among women diagnosed with DCIS is a consequence of the treatment choice or reflects the relatively benign nature of the disease-or both. Small tumor size has been associated with reduced mortality risk [40]; however, we did not find any significant effect. Seemingly, risk of death across ER expression profile tumors did not differ from that expected in the general population. These findings oppose those reported by Narod et al. [37] who showed shift in the survival curves towards an increase in the risk of death for ER-positive BC patients 10 years after diagnosis [37]. However, we have a small sample size and a large prevalence of missing/unclassified values. 
Table 3 Standardized Mortality Ratios (SMRs) of DCIS patients

\begin{tabular}{|c|c|c|c|c|c|c|}
\hline & Person-year & Obs deaths & Exp deaths & SMR & $95 \% \mathrm{CI}$ & AEM \\
\hline \multicolumn{7}{|l|}{ Age at diagnosis } \\
\hline$<50$ & 1716.9 & 10 & 2.9 & 3.44 & $(1.85 ; 6.40)$ & 4 \\
\hline $50-69$ & 3153.7 & 18 & 21.4 & 0.84 & $(0.53 ; 1.33)$ & -1 \\
\hline$>69$ & 556.1 & 28 & 29.2 & 0.96 & $(0.66 ; 1.39)$ & -2 \\
\hline \multicolumn{7}{|l|}{ Size } \\
\hline$>2 \mathrm{~cm}$ & 1021.9 & 10 & 12.40 & 0.8 & $(0.43 ; 1.50)$ & -2 \\
\hline$\geq 2 \mathrm{~cm}$ & 452.3 & 7 & 9.58 & 0.7 & $(0.35 ; 1.53)$ & -6 \\
\hline Unknown & 3967.9 & 39 & 31.65 & 1.2 & $(0.90 ; 1.69)$ & 2 \\
\hline \multicolumn{7}{|l|}{ Grade } \\
\hline I & 379.7 & 3 & 2.4 & 1.26 & $(0.41 ; 3.90)$ & 2 \\
\hline II & 613.2 & 3 & 4.5 & 0.66 & $(0.21 ; 2.05)$ & -2 \\
\hline III & 617.2 & 2 & 3.7 & 0.54 & $(0.13 ; 2.15)$ & -3 \\
\hline Unknown & 3831.9 & 48 & 43.0 & 1.12 & $(0.84 ; 1.48)$ & 1 \\
\hline \multicolumn{7}{|c|}{ Estrogen receptor } \\
\hline Positive & 2087.3 & 10 & 13.6 & 0.74 & $(0.40 ; 1.37)$ & -2 \\
\hline Negative & 594.2 & 8 & 9.6 & 0.83 & $(0.42 ; 1.67)$ & -3 \\
\hline Unknown & 2760.6 & 38 & 30.4 & 1.25 & $(0.90 ; 1.72)$ & 3 \\
\hline \multicolumn{7}{|l|}{ Surgery } \\
\hline Yes & 4224.7 & 39 & 37.6 & 1.04 & $(0.76 ; 1.42)$ & 0 \\
\hline No & 1206.6 & 16 & 15.7 & 1.02 & $(0.62 ; 1 ; 66)$ & 0 \\
\hline Unknown & 10.8 & 1 & 0.3 & 3.19 & $(0.45 ; 22.65)$ & 64 \\
\hline \multicolumn{7}{|c|}{ Hormonal treatment } \\
\hline Yes & 1466.8 & 7 & 8.4 & 0.83 & $(0.40 ; 1.75)$ & -1 \\
\hline No & 3151.3 & 41 & 34.7 & 1.18 & $(0.87 ; 1.60)$ & 2 \\
\hline Unknown & 8239.4 & 8 & 10.5 & 0.76 & $(0.38 ; 1.53)$ & 0 \\
\hline \multicolumn{7}{|l|}{ Radiotherapy } \\
\hline Yes & 1804.4 & 7 & 10.2 & 0.69 & $(0.32 ; 1.44)$ & -2 \\
\hline No & 2457.2 & 38 & 30.6 & 1.24 & $(0.90 ; 1.71)$ & 3 \\
\hline Unknown & 1180.5 & 11 & 12.8 & 0.86 & $(0.48 ; 1.55)$ & -2 \\
\hline \multicolumn{7}{|c|}{ Second invasive breast tumor } \\
\hline No & 5073.27 & 48 & 50.4 & 0.95 & $(0.72 ; 1.26)$ & 0 \\
\hline Yes & 368.80 & 8 & 3.2 & 2.51 & $(1.26 ; 5.02)$ & 13 \\
\hline \multicolumn{7}{|c|}{ Detection method $^{\mathrm{a}}$} \\
\hline Screening & 1109.02 & 3 & 5.72 & 0.52 & $(0.17 ; 1.63)$ & -2 \\
\hline Opportunistic & 931.34 & 53 & 47 & 1.13 & $(0.86 ; 1.48)$ & 6 \\
\hline Unknown & 20.94 & 0 & 0.90 & - & - & -43 \\
\hline Total & 5319.7 & 56 & 53.6 & 1.04 & $(0.80 ; 1.36)$ & 0 \\
\hline
\end{tabular}

Obs deaths observed deaths, Exp deaths expected deaths, SMR standardized mortality ratios, 95\% CI 95\% confidence interval, AEM absolute excess mortality

${ }^{a}$ Only women diagnosed from 2000 onwards and aged 50-69 were included as this is the time period and age range the population-based screening program operates within
Women aged $<50$ years old had $3.44(95 \%: 1.85 ; 6.40)$ times increased risk of dying compared to the general population $(\mathrm{AEM}=4)$ adding to the evidence of an excess mortality especially high among the youngest groups [15, $32,37]$. In addition, this group did not show a significant improvement in the mortality trends over the study period. Women aged less than 50 years old have been shown to present with more aggressive tumors [41], yet there was no significant difference in tumor characteristics by age group (Table 1). It is known that DCIS with invasive micro infiltrations clinically unrecognizable are common among young women [17]. Invasive infiltrations are considered an important risk factor of death after DCIS diagnosis [42]. This is supported by our results which showed a 2.5fold increase in the risk of death in women with a sIBC. Young women have been reported to develop sIBC up to twice more often than women aged $\geq 40$ years old [41, 43, 44]. In our cohort, the proportion of sIBC was slightly 
higher among the youngest patients (5.4\% vs. $2.7 \%$, data not shown). These differences were not significant, yet this may be explained by the small size of our population. To further explore this hypothesis, we conducted a sensitivity analysis excluding women with a secondary sIBC (Table S2) and found a substantial risk decrease $(\mathrm{SMR}=2.29 ; 95 \%$ CI $1.03 ; 5.10)$, suggesting that part of the increased risk of death in young women reported in the main analysis may be attributable to a second sIBC. Finally, hereditary cancer syndromes are associated with early onset of cancers as well as an increased risk of other cancer types such as of the digestive tract and female genitals $[43,45]$. This could explain the excess risk reported among young women and the higher prevalence of deaths from neoplasms other than breast (50 vs. $40 \%$ ) in this group.

In our cohort, circulatory system-related events were the second most frequent cause of death after cancer, representing a $21.4 \%$ of all deaths. Most non-neoplasm related deaths occurred among women aged over 50 years old and could be associated with comorbidities, as these are more common in advance stages of life [46]. However, numerous studies assessing competing causes of death highlight a concerning increase in death by causes other than $\mathrm{BC}[16$, 28]. Radiotherapy has been sometimes linked to long-term severe complications including increased morbidity associated with heart and lung disease [47-49], yet evidence remains controversial.

To the author's knowledge, this is the first populationbased study in Southern Europe comparing all-cause mortality rates of patients diagnosed with DCIS to the general population. Other strengths of our study include its population basis and the wide variety of tumor characteristics assessed. Limitations of the study include the impossibility to evaluate $\mathrm{BC}$ recurrences and second tumors other than $\mathrm{BC}$, the lack of completeness in numerous variables despite the exhaustive retrospective revision of all clinical histories, the lack of lifestyle and behavioral information, and the small size of our population. While our results should be further studied in larger cohorts of women, they can be regarded as a valuable estimate of mortality risk of an area from the Southern European setting and emphasize the importance of differential counselling of younger and older women diagnosed with DCIS.

Acknowledgements The authors wish to gratefully acknowledge the Girona Cancer Registry personnel for their dedication in running the registry process, and Prof. Marc Sáez, GRECS, University of Girona and CIBERESP, for his valuable advice in the statistical analysis.

Funding This work was partly funded by the CIBER of Epidemiology and Public Health (CIBERESP) through a pre-doctoral contract to M.S. No involvement of the funding sources in the study design, collection, analysis or interpretation of data.

\section{Compliance with ethical standards}

Conflict of interest The authors declare that they have no conflict of interest.

Ethical approval This study was in accordance with the ethical standards of the institutional and/or national research committee and with the 1964 Helsinki declaration and its later amendments or comparable ethical standards.

Informed consent The Epidemiology Unit and Girona Cancer Registry (GCR) is a statistical unit part of the Pla estadístic de Catalunya approved to produce official estiamtes of cancer incidence and mortality. The GCR studies are except of inform consent as they involve large datasets, are retrospective and observational, characteristics that make consent impractical to collect. Nonetheless, security measures are taken accordingly in order to protect patient confidentiality.

Open Access This article is distributed under the terms of the Creative Commons Attribution 4.0 International License (http://creativeco mmons.org/licenses/by/4.0/), which permits unrestricted use, distribution, and reproduction in any medium, provided you give appropriate credit to the original author(s) and the source, provide a link to the Creative Commons license, and indicate if changes were made.

\section{References}

1. Allred DC. Ductal carcinoma in situ: terminology, classification, and natural history. J Natl Cancer Inst Monogr. 2010;41:134-8.

2. Garfinkel L, Boring CC, Heath CW Jr. Changing trends: an overview of breast cancer incidence and mortality. Cancer. 1994;74:222-7.

3. Ferlay J, Steliarova-Foucher E, Lortet-Tieulent J, Rosso S, Coebergh JWW, Comber H, et al. Cancer incidence and mortality patterns in Europe: estimates for 40 countries in 2012. Eur J Cancer. 2013;49:1374-403.

4. Luke C, Priest K, Roder D. Changes in incidence of in situ and invasive breast cancer by histology type following mammography screening. Asian Pac J Cancer Prev. 2006;7(1):69-74.

5. Sørum R, Hofvind S, Skaane P, Haldorsen T. Trends in incidence of ductal carcinoma in situ: the effect of a population-based screening programme. Breast. 2010;19:499-505.

6. Van Steenbergen LN, Voogd AC, Roukema JA, Louwman WJ, Duijm LEM, Coebergh JWW, et al. Screening caused rising incidence rates of ductal carcinoma in situ of the breast. Breast Cancer Res Treat. 2009;115:181-3.

7. Li CI, Daling JR, Malone KE. Age-specific incidence rates of in situ breast carcinomas by histologic type, 1980 to 2001. Cancer Epidemiol Biomark Prev. 2005;14:1008-11.

8. Barchielli A, Federico M, De Lisi V, Bucchi L, Ferretti S, Paci E, et al. In situ breast cancer: incidence trend and organised screening programmes in Italy. Eur J Cancer. 2005;41:1045-50.

9. Puig-Vives M, Pollan M, Rue M, Osca-Gelis G, Saez M, Izquierdo A, et al. Rapid increase in incidence of breast ductal carcinoma in situ in Girona, Spain 1983-2007. Breast. 2012;21:646-51.

10. Schonberg MA, Marcantonio ER, Ngo L, Li D, Silliman RA, McCarthy EP. Causes of death and relative survival of older women after a breast cancer diagnosis. J Clin Oncol. 2011;29:1570-7.

11. Schopper D, de Wolf C. How effective are breast cancer screening programmes by mammography? Review of the current evidence. Eur J Cancer. 2009;45:1916-23. 
12. Deckert A. The existence of standard-biased mortality ratios due to death certificate misclassification - a simulation study based on a true story. BMC Med Res Methodol. 2016;16:1-9.

13. Penston James, Brewster David H. Should we use total mortality rather than cancer specific mortality to judge cancer screening programmes? BMJ. 2011;343:d6397.

14. Elshof LE, Schaapveld M, Schmidt MK, Rutgers EJ, van Leeuwen FE, Wesseling J. Subsequent risk of ipsilateral and contralateral invasive breast cancer after treatment for ductal carcinoma in situ: incidence and the effect of radiotherapy in a population-based cohort of 10,090 women. Breast Cancer Res Treat. 2016;159:553-63.

15. Bastiaannet E, Van De Water W, Westendorp RGJ, Janssen-Heijnen MLG, Van De Velde CJH, De Craen AJM, et al. No excess mortality in patients aged 50 years and older who received treatment for ductal carcinoma in situ of the breast. Int J Surg Oncol. 2012. https://doi.org/10.1155/2012/567506.

16. He W, Sofie Lindström L, Hall P, Czene K. Cause-specific mortality in women with breast cancer in situ. Int J Cancer. 2017; 140:2414-21.

17. Elshof LE, Schmidt MK, Rutgers EJT, van Leeuwen FE, Wesseling J, Schaapveld M. Cause-specific mortality in a populationbased cohort of 9799 women treated for ductal carcinoma in situ. Ann Surg. 2018;267:952-8.

18. Ernster VL, Barclay J, Kerlikowske K, Wilkie H, Ballard-barbash R. Mortality among women with ductal carcinoma in situ of the breast in the population-based surveillance, epidemiology and end results program. Arch Intern Med. 2000;160:953-8.

19. Ponti A, Lynge E, James T, Májek O, Von Euler-Chelpin M, Anttila $\mathrm{A}$, et al. International variation in management of screendetected ductal carcinoma in situ of the breast. Eur J Cancer. 2014;50:2695-704.

20. Kumar AS, Bhatia V, Henderson IC. Rates of ductal carcinoma in situ: a US perspective. Breast Cancer Res. 2005;7:271-5.

21. Lynge E, Ponti A, James T, Majek O, von Euler-Chelpin M, Anttila A. Variation in detection of ductal carcinoma in situ (DCIS) during screening mammography A survey within the International Cancer Screening Network (ICSN). Eur J Cancer. 2014;50(1):185-92.

22. Cambra MJ, Farrús B, Moreno F, Anglada L, Arenas M, Ballester R, et al. Management of breast ductal carcinoma in situ in Catalonia, Spain: results from the Grup Oncologic Calalà-OccitàCatalonia survey with 9-year follow up. Breast. 2017;35:196-202.

23. Generalitat de Catalunya. Institut d'Estadística de Catalunya [Internet]. 2016. http://www.idescat.cat. Accessed 12 Jun 2017.

24. Izquierdo Font À, Marcos-Gragera R, Vilardell Gil ML, Fuentes Fernández J, Vidal Vila A. CanGir. El càncer a Girona 2010 2012, Projeccions de la incidència 2017; 2016 p. 90. http://ico. gencat.cat/ca/professionals/serveis_i_programes/registre_del_ cancer/.

25. StataCorp. Stata statistical software: release 13. College Station: StataCorp; 2013.

26. Generalitat de Catalunya. Càncer. Detecció precoç de càncer de mama [Internet]. 2016. http://ico.gencat.cat/ca/el-cancer/progr ames_de_deteccio_precoc/programa_de_deteccio_precoc_de_ cancer_de_mama/. Accessed 27 Nov 2016.

27. GENCAT. El Programa de Detecció Precoç de Càncer de Mama de Girona [Internet]. 2018. http://ics.gencat.cat/ca/detall/notic ia/GTGirona_deteccio_precoc_cancer_mama. Accessed 11 Nov 2018.

28. Worni M, Akushevich I, Greenup R, Sarma D, Ryser MD, Myers ER, et al. Trends in treatment patterns and outcomes for ductal carcinoma in situ. J Natl Cancer Inst. 2015;107:djv263.

29. Harding C, Pompei F, Burmistrov D, Welch HG, Abebe R, Wilson R. Breast cancer screening, incidence, and mortality across US counties. JAMA Intern Med. 2015;175:1483-9.
30. Ripping TM, Verbeek ALM, Fracheboud J, De Koning HJ, Van Ravesteyn NT, Broeders MJM. Overdiagnosis by mammographic screening for breast cancer studied in birth cohorts in the Netherlands. Int J Cancer. 2015;137:921-9.

31. Jacklyn G, Glasziou P, Macaskill P, Barratt A. Meta-analysis of breast cancer mortality benefit and overdiagnosis adjusted for adherence: improving information on the effects of attending screening mammography. Br J Cancer. 2016;114:1269-76.

32. Ernster VL, Barclay J, Kerlikowske K, Wilkie H, Ballard-Barbash R. Mortality among women with ductal carcinoma in situ of the breast in the population-based surveillance, epidemiology and end results program. Arch Intern Med. 2000;160:953-8.

33. Lee JRJ, Vogel VG. Who uses screening mammography regularly? Cancer Epidemiol Biomark Prev. 1995;4:901-6.

34. Hofer TP, Katz SJ. Healthy behaviors among women in the United States and Ontario: the effect on use of preventive care. Am J Public Health. 1996;86:1755-9.

35. Marmot MG, Altman DG, Cameron DA, Dewar JA, Thompson SG, Wilcox M. The benefits and harms of breast cancer screening: an independent review. Br J Cancer. 2013;108:2205-40.

36. Giannakeas V, Sopik V, Narod SA. Association of radiotherapy with survival in women treated for ductal carcinoma in situ with lumpectomy or mastectomy. JAMA Netw Open. 2018;1:e181100.

37. Narod SA, Iqbal J, Giannakeas V, Sopik V, Sun P. Breast cancer mortality after a diagnosis of ductal carcinoma in situ. JAMA Oncol. 2015;1:888-96.

38. Early Breast Cancer Trialists' Collaborative Group (EBCTCG), Correa C, McGale P, Taylor C, Wang Y, Clarke M, et al. Overview of the randomized trials of radiotherapy in ductal carcinoma in situ of the breast. JNCI Monogr. 2010;2010:162-77.

39. Sagara Y, Freedman RA, Vaz-Luis I, Mallory MA, Wong SM, Aydogan F, et al. Patient prognostic score and associations with survival improvement offered by radiotherapy after breast-conserving surgery for ductal carcinoma in situ: a population-based longitudinal cohort study. J Clin Oncol. 2016;34:1190-6.

40. Wadsten C, Garmo H, Fredriksson I, Sund M, Wärnberg F. Risk of death from breast cancer after treatment for ductal carcinoma in situ. Br J Surg. 2017;104:1506-13.

41. Goldstein NS, Vicini FA, Kestin LL, Thomas M. Differences in the pathologic features of ductal carcinoma in situ of the breast based on patient age. Cancer. 2000;88:2553-60.

42. Ellis IO, Lee AHS, Elston CW, Pinder SE. Microinvasive carcinoma of the breast: can it be diagnosed reliably and is it clinically significant? Histopathology. 1999;35:468-72.

43. Sackey H, Hui M, Czene K, Verkooijen H, Edgren G, Frisell J, et al. The impact of in situ breast cancer and family history on risk of subsequent breast cancer events and mortality - a populationbased study from Sweden. Breast Cancer Res. 2016;18:105.

44. Falk RS, Hofvind S, Skaane P, Haldorsen T. Second events following ductal carcinoma in situ of the breast: a register-based cohort study. Breast Cancer Res Treat. 2011;129:929-38.

45. Apostolou P, Fostira F, Baudi F. Hereditary breast cancer: the era of new susceptibility genes. Biomed Res Int. 2013;2013:11.

46. Divo MJ, Martinez CH, Mannino DM. Ageing and the epidemiology of multimorbidity. Eur Respir J. 2014;44:1055-68.

47. Darby SC, Ewertz M, McGale P, Bennet AM, Blom-Goldman U, Brønnum D, et al. Risk of ischemic heart disease in women after radiotherapy for breast cancer. N Engl J Med. 2013;368:987-98.

48. Meric F, Buchholz TA, Mirza NQ, Vlastos G, Ames FC, Ross MI, et al. Long-term complications associated with breast-conservation surgery and radiotherapy. Ann Surg Oncol. 2002;9:543-9.

49. Boekel NB, Schaapveld M, Gietema JA, Rutgers EJT, Versteegh MIM, Visser O, et al. Cardiovascular morbidity and mortality after treatment for ductal carcinoma in situ of the breast. JNCI J Natl Cancer Inst. 2014;106(8):dju156. 